Supplementary Information for

\title{
Roles of Polymerized Anionic Clusters Stimulating for Hydrolysis Deterioration in $\mathrm{Li}_{7} \mathrm{P}_{3} \mathrm{~S}_{11}$
}

\author{
Ji-Su Kim, ${ }^{\dagger}, \$$ Wo Dum Jung, ${ }^{\dagger}, \not, \$$ Sung Soo Shin, ${ }^{\dagger}$ Sungeun Yang, ${ }^{\dagger}$ Sangbaek Park, ${ }^{\dagger}$ Jong-Ho \\ Lee, ${ }^{\dagger}$ Byung-Kook Kim, ${ }^{\dagger}$ Jong-Heun Lee,,${ }^{\dagger}$ and Hyoungchul Kim ${ }^{*}{ }^{\dagger}$ \\ ${ }^{\dagger}$ Energy Materials Research Center, Korea Institute of Science and Technology, 5 Hwarang-ro \\ 14-gil, Seongbuk-gu, Seoul 02792, Republic of Korea \\ †Department of Materials Science and Engineering, Korea University, 145 Anam-ro, Seongbuk- \\ gu, Seoul 02841, Republic of Korea
}

\section{Corresponding Author}

E-mail address: hyoungchul@kist.re.kr (H. Kim) 


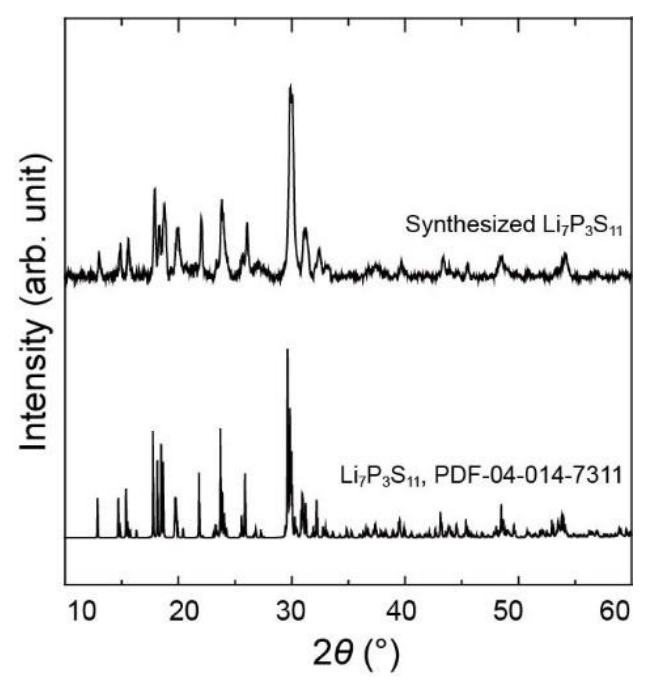

Figure S1. X-ray powder diffraction pattern of synthesized $\mathrm{Li}_{7} \mathrm{P}_{3} \mathrm{~S}_{11}$. The glass-ceramic $\mathrm{Li}_{7} \mathrm{P}_{3} \mathrm{~S}_{11}$ was well synthesized without any secondary and $\mathrm{LiOH}$ phases from the results of X-ray diffraction analysis. 


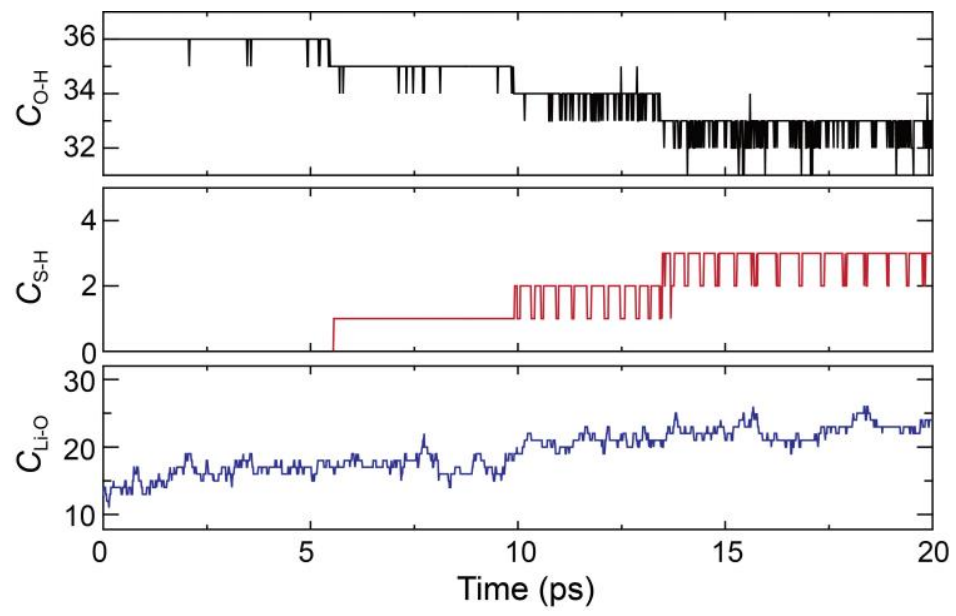

Figure S2. Variations in the number of $\mathrm{O}-\mathrm{H}, \mathrm{S}-\mathrm{H}$, and Li-O bonds during ab-initio molecular dynamics simulations for $20 \mathrm{ps}$. 


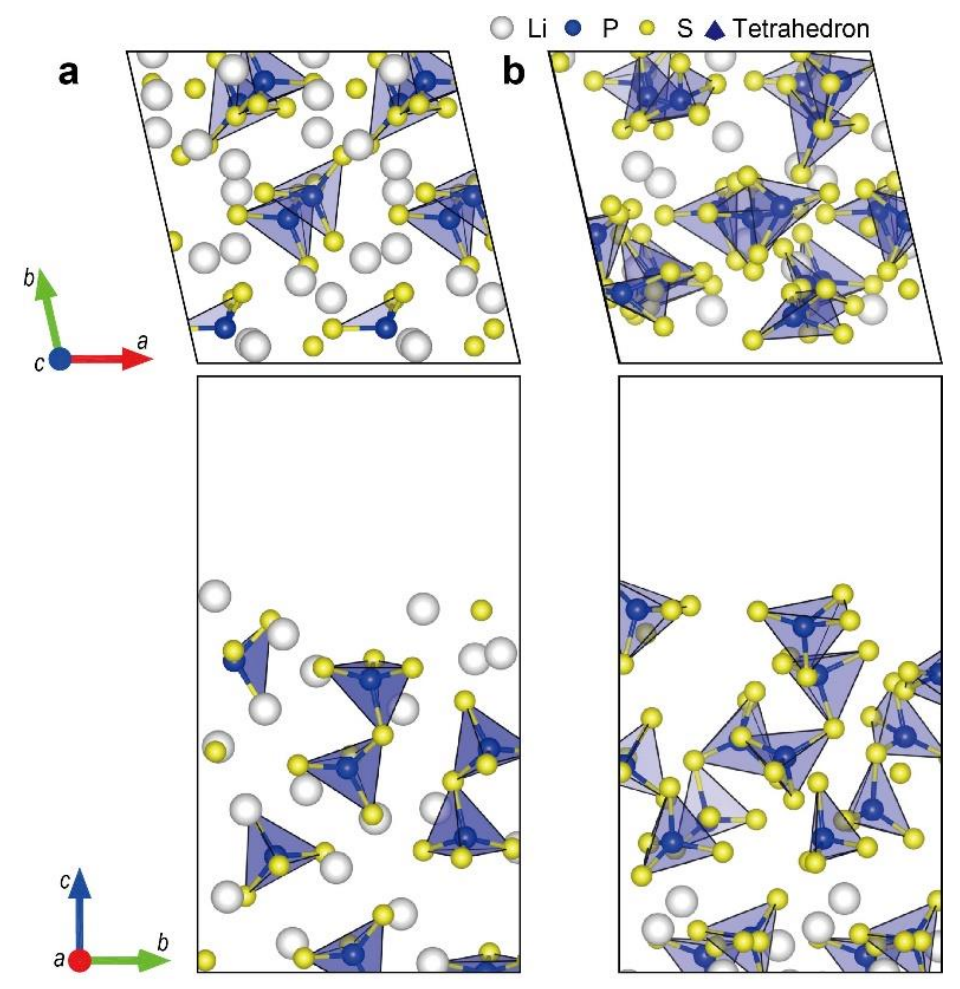

Figure S3. (a) Clean and (b) delithiated (100) $\mathrm{Li}_{7} \mathrm{P}_{3} \mathrm{~S}_{11}$ surfaces. The white, blue, and yellow spheres indicate the $\mathrm{Li}, \mathrm{P}$, and $\mathrm{S}$ ions, respectively. The blue tetrahedra correspond to the anion clusters. 
Table S1. Optimized lattice parameters of $\mathrm{Li}_{7} \mathrm{P}_{3} \mathrm{~S}_{11}$ unit cells.

\begin{tabular}{ccccccc}
\hline \multicolumn{3}{c}{ Lattice constant $(\AA)$} & \multicolumn{3}{c}{ Lattice angle $\left(^{\circ}\right)$} & \multirow{2}{*}{ Note } \\
\cline { 1 - 5 }$a$ & $b$ & $c$ & $\alpha$ & $\beta$ & $\gamma$ & \\
\hline 12.67 & 6.32 & 12.55 & 102.81 & 113.94 & 73.18 & This work \\
12.58 & 6.06 & 12.61 & 102.94 & 113.17 & 74.76 & Experiment $^{1}$ \\
12.49 & 6.03 & 12.53 & 102.83 & 113.27 & 74.52 & Experiment $^{1}$ \\
12.84 & 6.20 & 12.64 & 103.72 & 113.78 & 74.09 & Computation $^{1}$ \\
12.50 & 6.03 & 12.53 & 102.85 & 113.20 & 74.47 & Experiment $^{2}$ \\
12.48 & 6.03 & 12.45 & 102.91 & 113.30 & 74.50 & Experiment $^{3}$ \\
\hline
\end{tabular}




\section{Supplementary References}

1. Chu, I.-H.; Nguyen, H.; Hy, S.; Lin, Y.-C.; Wang, Z.; Xu, Z.; Deng, Z.; Meng, Y. S.; Ong, S. P. Insights into the performance limits of the $\mathrm{Li}_{7} \mathrm{P}_{3} \mathrm{~S}_{11}$ superionic conductor: a combined first-principles and experimental study. ACS Appl. Mater. Interfaces 2016, 8, $7843-7853$.

2. Yamane, H.; Shibata, M.; Shimane. Y.; Junke, T.; Seino, Y.; Adams S.; Minami, K.; Hayashi, A.; Tatsumisago, M. Crystal structure of a superionic conductor, $\mathrm{Li}_{7} \mathrm{P}_{3} \mathrm{~S}_{11}$. Solid State Ionics 2007, 178, 1163-1167.

3. Onodera, Y.; Mori, K.; Otomo, T.; Sugiyama, M.; Fukunaga, T. Structural evidence for high ionic conductivity of $\mathrm{Li}_{7} \mathrm{P}_{3} \mathrm{~S}_{11}$ metastable crystal. J. Phys. Soc. Jpn. 2012, 81, 044802 . 